\title{
Esclerosis peritoneal: análisis de dos casos
}

\author{
Ana Fernández-Viña Fernández - Rosario Reguera Álvarez - Isabel González Díaz
}

Unidad de Diálisis Peritoneal. Hospital Universitario Central de Asturias, Oviedo

\section{Introducción}

La peritonitis esclerosante (PE) es una grave complicación de la Diálisis Peritoneal (DP), con una incidencia que varía del 0,7 a 7,3\% según las series consultadas ${ }^{1}$. Su causa es desconocida, aunque influyen varios factores etiológicos: exposición a soluciones no biocompatibles, estímulo inflamatorio sobre impuesto: peritonitis, biofilm de catéteres, cirugía abdominal, acetato, desinfectantes, lavados con suero salino, hemoperitoneo, betabloqueantes. El pronóstico dependerá fundamentalmente del diagnóstico precoz.

Presentamos a continuación dos casos clínicos en los que se ha producido una peritonitis esclerosante, con el objetivo de analizar esta patología, poco frecuente, pero muy grave y considerar las posibles actuaciones preventivas, a través de una visión enfermera.

\section{CASO 1}

El primer caso, se trata de una mujer de 25 años diagnosticada de síndrome de Laurence-Moon-Biell que se manifiesta con hipogonadismo con obesidad, retraso mental, polidactilia, retinitis pigmentaria e insuficiencia renal. Inició tratamiento de HD a los 11 años, recibió su primer trasplante renal al año siguiente, que falló a causa de una trombosis venosa, por lo que retornó a HD y precisó trasplantectomía 9 meses más tarde.

Debido a dificultades de acceso vascular, necesitó ser derivada a DP. En la evolución la paciente sufrió varios episodios de peritonitis y padeció un hiperparatiroidismo grave. Su membrana peritoneal, se clasificó como medio-alta transportadora. Tras 12 años en programa de DP, la paciente muestra un mal estado

\begin{tabular}{|c|}
\hline Correspondencia: \\
Ana Fernández-Viña Fernández \\
C/ Illas 5-5 izquierda \\
33012 Oviedo \\
anafvf@gmail.com
\end{tabular}

general y una peritonitis, causada por dos gérmenes (Staphilococcus epidermidis y Pseudomona aeruginosa), junto con infección de túnel por el estafilococo. En la exploración se apreció un "efecto masa" en la zona del túnel subcutáneo, no fluctuante, sin signos inflamatorios, de consistencia dura y contorno mamelonado, produciendo una eventración peritoneal en el orificio del catéter.

En las imágenes radiológicas (figura 1) se apreció la esclerosis y calcificación de toda la membrana peritoneal, comprimiendo todas las estructuras viscerales abdominales. Se procedió a tratamiento antibiótico específico, retirada de catéter de DP, y transferencia a HD. Más tarde, la paciente presenta dificultad para la ingesta por vómitos. Una vez en HD desarrolló dos nuevos episodios de ascitis, secundaria a peritonitis por Echerichia coli, que precisó evacuación mediante paracentesis. Posteriormente, presentó una isquemia aguda en miembro inferior derecho, por obstrucción femoropoplítea.

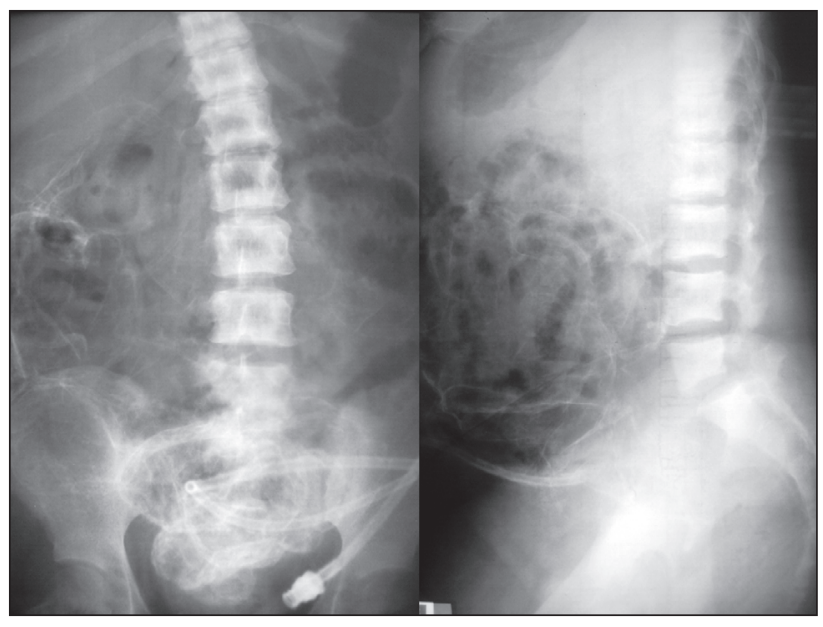

Figura 1. Caso 1. Imagen radiológica de la peritonitis esclerosante

Se desestimó el tratamiento quirúrgico de la calcificación peritoneal y la amputación del miembro isquémico. La evolución fue insatisfactoria falleciendo poco después. 


\section{CASO 2}

Se trata de un varón de 48 años, con antecedentes de obesidad, diabetes mellitus tipo 2 controlada con dieta y tabaquismo, que fue diagnosticado de insuficiencia renal secundaria a glomerulonefritis rápidamente progresiva, con anticuerpos antimembrana basal glomerular. Por este motivo, recibió tratamiento inmunosupresor con esteroides, ciclofosfamida y también plasmaféresis, todo ello, sin resultado satisfactorio para su función renal.

Inicialmente recibió tratamiento renal sustitutivo mediante HD y posteriormente pasó a DP. Durante los 5 años en esta técnica, el paciente desarrolló 10 episodios de peritonitis, 9 de ellos por Staphilococcus (8 epidermidis y 1 capitis). El último de ellos por Candida albicans, que motivó la retirada del catéter de DP y su transferencia a HD. Durante el tratamiento con DP se transformó en un "alto transportador".

Seis meses después del cambio de modalidad terapéutica, el paciente sufre cuadro de dolor abdominal con vómitos, pérdida de peso, distensión abdominal y efecto masa en hipogastrio. Se realizó ecografía abdominal, apreciándose marcada dilatación del estómago y asa proximal del intestino delgado, que presenta pared moderadamente engrosada; colección de líquido con múltiples septos en hipogastrio.

También se realizó una tomografía axial computorizada (TAC) abdominal (figura 2), donde se constató la existencia de una pequeña cantidad de líquido perihepático además de periesplénico, con engrosamiento peritoneal, asociada a colección líquida pélvica con septos en su interior que engloba asas de intestino delgado, condicionando gran dilatación gástrica, duodenal y de yeyuno, con niveles hidroaéreos, lo cual condujo al diagnóstico de esclerosis peritoneal.

Por otra parte, al paciente se le propuso tratamiento quirúrgico, que desestimó.

La evolución fue tórpida, con varios ingresos por cuadros de oclusión intestinal, precisando alimentación parenteral, administración sin éxito de esteroides y progresivo deterioro de su estado, con ascitis y desnutrición que motivaron su fallecimiento a los 6 meses del diagnóstico.

\section{Resultados y Discusión}

La esclerosis peritoneal es una patología que provoca una alta morbimortalidad, por lo que nuestros esfuerzos deben ir dirigidos a la prevención y al diagnóstico precoz que puede modificar la supervivencia del paciente. Tenemos una serie de marcadores predictivos de esta entidad, como son el tiempo en DP, el que sea alto transportador, y factores predisponentes como son, el hiperparatiroidismo grave (primer caso) o los episodios de peritonitis de repetición (en el segundo). Hay que tener en cuenta, que más de la mitad de los casos, se producen tras el abandono de la técnica de DP.

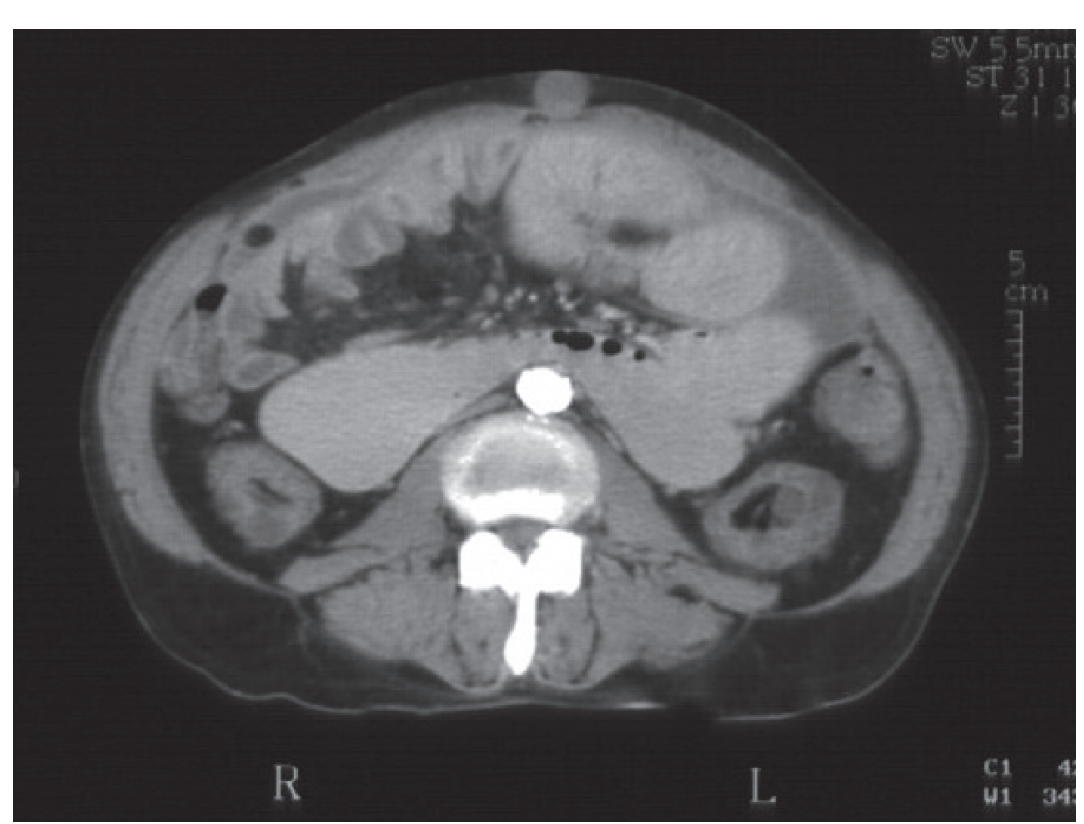

El diagnóstico se efectúa mediante pruebas de imagen: Rx simple, ecografía o TAC abdominal, aunque el diagnóstico definitivo se puede obtener mediante biopsia peritoneal, donde se puede apreciar, un aumento del tamaño de los fibroblastos, depósito de fibrina, angiogénesis capilar, sangrado perivascular e infiltración de mononucleares.

El tratamiento de este grave cuadro, dependerá del grado de afectación peritoneal. En los estadios iniciales podría ser suficiente el reposo peritoneal; con lavados peritoneales y esteroides. En casos más avanzados se necesitará tratamiento inmunosupresor (ciclofosfamida, azatioprina, ciclosporina) e incluso tamoxifeno. En casos extremos

Figura 2. Caso 2. Tomografia axial computorizada 
con compromiso visceral, puede ser necesario recurrir a la cirugía, realizando enterolisis, técnica que tiene una mortalidad entre $40-80 \%$.

Entre las medidas de prevención del desarrollo de la peritonitis esclerosante, cabe destacar la importancia del papel de enfermería en el entrenamiento del paciente para reducir al máximo los episodios de peritonitis y tratarlos adecuadamente de forma precoz; además debemos utilizar soluciones lo más biocompatibles posible, evitando de ese modo altas concentraciones de glucosa. Así mismo, es muy importante el control del hiperparatiroidismo secundario en los pacientes urémicos.

Finalmente, debemos estar alerta en aquellos pacientes que se convierten en altos transportadores con el paso del tiempo en DP. Por tanto, es conveniente realizar un PET (test de equilibrio peritoneal), al menos una vez al año y tras episodios de peritonitis.

\section{Bibliografía}

1. Agarwal A, Yeh BM, Breiman RS, Qayyum A, Coakley FV. Peritoneal calcification: causes and distinguishing features on CT. Am J Roentgenol 2004; 182: 441-445.

2. Di Paolo N, Sacchi G, Lorenzoni P, Sansoni E, Gaggiotti $E$. Ossification of the peritoneal membrane. Perit Dial Int. 2004; 24: 471-477.

3. Fletcher S, Gibson J, Brownjohn AM. Peritoneal calcification secondary to severe hyperparathyroidism. Nephrol Dial Transplant. 1998; 13: 2656-2658.

4. Kawaguchi $Y$, Saito A, Kawanishi H, Nakayama M, Miyazaki M, Nakamoto $H$, Tranaeus A. Recommendations on the management of encapsulating peritoneal sclerosis in Japan, 2005: diagnosis, predictive markers, treatment, and preventive measures. Perit Dial Int. 2005; 25 Suppl 4: S83-95.

5. Kawanishi H, Watanabe H, Moriishi M, Tsuchiya S. Successful surgical management of encapsulating peritoneal sclerosis. Perit Dial Int 2005; 25 Suppl 4: S39-S47.

6. Ubara $Y$, Katori H, Tagami T, Yokota M, Kitamura A, Matsushita $Y$, Takemoto F, Imai T, Inoue $S$, Kuzuhara K, Hara S, Yamada A, Takagawa R. Severe ectopic calcification of the intestinal wall in a patient on long-term continuous ambulatory peritoneal dialysis therapy. Am J Kidney Dis. 2000; 35: 761-766. 